\title{
ESTRATÉGIAS DE LEITURA E LITERATURA INFANTIL CAPIXABA: FORMANDO LEITORES NA EMEF CUSTÓDIA DIAS DE CAMPOS
}

\section{READING STRATEGIES AND CHILDREN'S LITERATURE CAPIXABA: FORMING READERS IN EMEF CUSTÓDIA DIAS DE CAMPOS}

\author{
Ivana Esteves Passos de Oliveira* \\ Renata Junqueira de Souza**
}

\begin{abstract}
Resumo: Este artigo é fruto de reflexões oriundas de uma pesquisa de pós-doutoramento, com bolsa Capes-Procrad, realizada na Unesp-PP, contemplando estágio no Centro de Estudos em Leitura e Literatura Infantil e Juvenil (CELLIJ), para aquisição de repertório teórico das estratégias de compreensão leitora com literatura infantil e também de uma pesquisa de observação participante e pesquisa-ação. A proposição é a implementação de uma oficina de estratégias de leitura com literatura infantil, no Espírito Santo, com alunos do quarto ano das séries iniciais da EMEF Custódia Dias de Campos, escola municipal de Vitória. O locus onde se realiza a oficina é a biblioteca da escola, espaço em que transcorrem as práticas de leitura literária dos alunos, com a supervisão da bibliotecária. A pesquisaação, contemplando prática guiada pela pesquisadora-oficieneira, foi embasada nas estratégias de leitura de Isabel Sólé (1996) e nos estudos de compreensão leitora de Girotto e Souza (2010).
\end{abstract}

Palavras-chave: Literatura Infantil. Letramento Literário. Estratégias de Leitura.

\begin{abstract}
This article is the result of reflections from a post-doctoral research, with a Capes-Procrad scholarship, held at Unesp-PP, contemplating an internship at the Center for Studies in Reading and Children's and Youth Literature (CELLIJ), to acquire a theoretical repertoire of reading comprehension strategies with children's literature, as well as participant observation research and action research. The proposal is the implementation of a reading strategies workshop with children's literature, in Espírito Santo, with fourth year students of the initial series of the Custódia Dias de Campos, municipal school of Vitória. The locus where the workshop is held is the school library, a place where students' literary reading practices take place, with the supervision of the librarian. The action research, contemplating practice guided by the researcher-official, was based on the reading strategies of Isabel Sólé (1996) and the reading comprehension studies of Girotto e Souza (2010).
\end{abstract}

Keywords: Children's Literature. Literary Literature. Reading Strategies.

\section{Literatura na escola}

Mesmo em face aos investimentos do governo em programas de fomento à leitura, como o Programa Nacional de Biblioteca na Escola - PNBE, a qualidade da leitura literária no ambiente escolar parece não ter evoluído muito. Assim como a escola, a literatura infantil foi criada com o propósito de ser um instrumento a mais no processo de manipulação da criança no acatamento da norma vigente dominante, que era então a da burguesia emergente. A obra literária destinada às crianças tinha o papel

\footnotetext{
* Ivana Esteves Passos de Oliveira - Professora de Língua Portuguesa na Licenciatura em Música da Faculdade de Música do Espírito Santo (Fames). Estágio de Pós-Doutorado em Estratégias de Leitura com a Literatura Infantil do Espírito Santo, no Centro de Pesquisas em Leitura e Literatura Infantil e Juvenil (CELLIJ), Faculdade de Ciências e Tecnologia da UNESP (Presidente Prudente). Doutora em Letras pela Universidade Federal do Espírito Santo. E-mail: ivanaesteves@yahoo.com

** Livre docente em Conteúdos e Metodologia de Língua Portuguesa. Pós doutorado no departamento de Literatura e Ensino da Ohio State University. Docente da graduação e pós graduação da Faculdade de Ciências e Tecnologia da UNESP (Presidente Prudente). Coordenadora do Centro de Pesquisas em Leitura e Literatura Infantil e Juvenil (CELLIJ). Com experiência na área de Educação e Literatura, com ênfase em Ensino-Aprendizagem, atuando principalmente nos seguintes temas: Leitura e Ensino, Literatura e Ensino, Estratégias de leitura. Compreensão de textos. E-mail: recellij@gmail.com
} 
de reproduzir o mundo adulto, por meio da transmissão de conceitos e padrões de comportamento consonantes às demandas da sociedade.

A ficção destinada à criança tinha, no seu aspecto formal, mediante a utilização da linguagem manipulada, a capacidade de intensificar a intencionalidade do discurso moralizante. Ainda hoje o simbolismo inerente à literatura infantil é, muitas vezes, utilizado prioritariamente a serviço das demandas da educação e da escola. Esta, tida como grande ativadora do mercado de livros infantis vive hoje um impasse sobre a natureza e destinação da literatura infantil: se para educação, formação e informação ou para diversão, deleite e reflexão crítica.

O direcionamento didático-pedagógico é explícito. A valorização da literatura infantil no século XXI ainda incorpora premissas relacionadas a uma escrita funcional, em atendimento à escola e com observância ao estímulo à leitura. Zilberman (2003) observa que os fatores estruturais de um texto de ficção - narrador, visão de mundo, linguagem - podem se converter a partir da mediação do adulto. É o aspecto de formação do texto infantil o que o mantém próximo da pedagogia. São mais legíveis que escrevíveis; assim seriam os livros infantis tradicionais, conforme a categorização de Barthes (apud HUNT, 2010, p. 127):

São textos fechados que o leitor experiente lê 'aquém da capacidade'. Em outras palavras, o escritor tentou fazer todo o trabalho para o leitor, para limitar as possibilidades de interpretação e para fortemente orientar o entendimento. O texto escrevível, por outro lado, é muito mais 'aberto' a contribuições do leitor. Ao tentar controlar o texto de várias maneiras, os escritores, por insinuação, exigem que os leitores leiam apenas dentro de limites implícitos e definidos, e os textos se tornam, nos termos do teórico Mikhail Bakhtin, 'mais monólogos' que ‘dialógicos' ou 'polifônicos'. (BARTHES apud HUNT, 2010, p. 127):

As mediações escolares de leitura literária, apesar da melhor das boas intenções de pedagogos, professores e bibliotecários, transitam, conforme Sueli Cagneti, em artigo publicado na obra Livro que te quero livre (2005), por caminhos de transmissão que apregoam o enquadramento dos livros em gêneros, escolas, fichas e em cobranças de sentido utilitaristas acerca do conhecimento obtido com as obras.

No ensino fundamental, as mediações de leitura literária ainda são pautadas e prescritas nos PCNs ${ }^{1}$, documento que, como é sabido, traz orientações curriculares para a escola brasileira, no uso da literatura. As mediações de leitura são distanciadas da indução à formação do gosto pela literatura, sobretudo, pelo fato de que formar o gosto demanda apropriação cultural e tempo disponível.

O caminho do empoderamento da criança leitora - por meio da leitura-livremediada - parece um percurso mais condizente a ser adotado pela escola nas séries iniciais do ensino fundamental, no intuito de salvaguardar a liberdade de fruição do leitor e induzir-lhe ao prazer de ler para descobrir o mundo.

A formação do gosto pela fruição literária, em entrelace ao empoderamento cultural, são os delineamentos que norteiam a investigação exposta nesse artigo, e pauta-se na convicção de que a paixão das crianças pelos livros de literatura advém por meio do estímulo e do acesso. Para tanto, se faz premente que o ensinar a ler ocorra não no aspecto da decodificação, mas levando os jovens leitores à compreensão do texto e

\footnotetext{
${ }^{1}$ Parâmetros Curriculares Nacionais: língua portuguesa/Secretaria de Educação Fundamental - Brasília 1997.
} 
oportunizando-lhes a aquisição de significado ao que leem, ensinando-lhes a escutar a polifonia textual e a diversidade polissêmica.

\section{Compreensão leitora}

A metodologia ensejada nesse estudo é a das estratégias de compreensão leitora, uma metologia norte-americana originária dos estudos de metacognição que, de acordo com Santos e Souza (2011), aponta quatro direcionamentos para a compreensão durante a leitura: conhecimento prévio/experiências do leitor, das características do texto que o aluno está lendo, do contexto da leitura e das estratégias aplicadas no processo de leitura.

Nessa cartografia literária, desvendar o seu entorno pode suscitar mais envolvimento e estabelecer conexões que promovam o alinhave do leitor com a obra, a partir do entrelace do texto com o seu mundo de leitor. Nesse aspecto, é que a Oficina de estratégias de leitura com livros produzidos por autores do Espírito Santo na EMEF Custódia Dias de Campos - prática que consubstanciou a pesquisa de campo -, alcança justificativa plausível. Em face às oficinas, pôde-se perceber a possibilidade de conferir mais visibilidade e relevância aos autores que produzem literatura infantil e/ou livros paradidáticos no estado do Espírito Santo.

\section{Obras do Espírito Santo}

A falta de acessibilidade às obras dos escritores que produzem literatura no Espírito Santo, já é uma característica do "mercado literário" local, a ponto de torná-los quase que invisíveis. Tal fato foi apurado em recente pesquisa de doutorado, intitulada: "O desvelar do autor produtor, divulgador e distribuidor de livro infantil no Espírito Santo no século XXI","

Na capital do Estado, Vitória, a única livraria de origem capixaba, a Livraria Logos, que disponibilizava de um espaço destinado aos autores de livros produzidos no Estado, fechou em 2015 quatro lojas, ficando apenas com uma loja em um shopping de bairro e outra, que serve de estoque, onde funciona o escritório. E a partir de 2017 passou a funcionar somente como distribuidora. A livraria La Selva, que operava no aeroporto de Vitória, encerrou suas atividades no estado em meados de 2016. No mesmo período, a Livraria Leitura, situada no Shopping Vitória, o maior da capital, também fechou suas portas.

Restam agora a Livraria SBS, e a Livraria Saraiva, uma livraria de shopping, e cujo acesso à venda de livros de autores capixabas é dificultado. Para se conseguir incluir títulos em seu acervo, apenas por mediação de distribuidores, visto que, para figurar no cadastro de editoras ligadas diretamente à Saraiva, somente com 150 títulos no catálogo. Para uma editora independente e fora do eixo Rio-São Paulo, ou para um autor independente, essa parece ser uma empreitada inimaginável.

Essa inacessibilidade já fora percebida pelo escritor de livros infantis, Monteiro Lobato (apud PACHECO, 1985), quando este declara, nos idos de 1919, em relação, até mesmo, dos livros de escritores de fora do Estado. “[...] o Espírito Santo me parece uma

\footnotetext{
${ }^{3}$ OLIVEIRA, Ivana Esteves Passos de, O desvelar do autor, produtor, divulgador e distribuidor de literatura infantil no Espírito Santo no século XXI, 2015. Tese de doutorado em Letras, Universidade Federal do Espírito Santo (Ufes).
} 
ficção geográfica, onde não tenho uma só livraria, nem um só assinante". ${ }^{3}$ Essa "ficção geográfica" em relação à oferta do produto livro, é notadamente pior a respeito da literatura regional, conforme descrito anteriormente.

Em face a esse contexto, o hipotético candidato a leitor das obras de autores capixabas tem que percorrer uma verdadeira via crucis para acessar esses livros. Essa dificuldade afasta os potenciais leitores da produção literária local. Existem algumas papelarias que aceitam receber os livros em consignação e que promovem alguns eventos de divulgação na capital. Em municípios vizinhos existem algumas outras, que recebem e comercializam, pontualmente, conforme demanda escolar, livros de escritores do Estado - como a Livraria do Estudante, no centro da cidade de Vila Velha.

Em um tímido trabalho de distribuição feito por um autor de livros infantis nas escolas, os relatos costumam ser, invariavelmente, de que se ouve falar dos escritores, mas não se sabe onde encontrá-los. Paradoxalmente, a grande maioria dos escritores estão com seus livros em casa e sem saber o que fazer com eles, aguardando por uma demanda espontânea.

É notável e pesquisas apontam que a produção da literatura regional do Espírito Santo vem crescendo, tanto de livros de literatura infantil e como de paradidáticos, em vista das facilidades das leis de incentivo à cultura e pelos editais do Governo do Estado. Mas os mecanismos de distribuição e de acessibilidade ainda ocorrem na modalidade artesanal; pois não existe no Espírito Santo nenhuma iniciativa de ordem pública para profissionalizar a divulgação e a distribuição.

Há algumas poucas editoras locais independentes, mas pouco focadas na divulgação e distribuição dos livros dos autores capixabas. Não fosse o trabalho isolado de escritores - que atuam como agentes criativos - desenvolverem iniciativas inovadoras, no intuito de envolver e encantar o seu público infantil nas escolas visando prospectar a venda de seus livros e divulgar o seu trabalho.

Há que se atentar para o propósito sócio-cultural desse estudo, cuja urgência é de proposições que possam assegurar mais experiências literárias na escola, no intuito de formar um público leitor de literatura infantil e juvenil; bem como para oferecer soluções para a falta de acesso à literatura regional do Espírito Santo. O estudo das estratégias de compreensão leitora visa unir essas duas pontas soltas no contexto da educação e da literatura. A oficina das estratégias, com a utilização de textos regionais, tem como desafio traduzir-se em uma oportunidade para empoderamento da criança leitora, permitindo-lhe conhecer a sua cultura e reforçar a sua identidade cultural por meio de obras da literatura de seu Estado. De acordo com Oliveira,

Compreender o mercado (produção, publicação, divulgação e distribuição) de literatura infantil no Espírito Santo parece ser de suma importância na intenção de descortinar a constituição de processos identitários no contexto capixaba e permitir que, desde a mais tenra idade, a criança possa refazer e recompor a sua territorialidade, pelo acesso a um acervo ficcional. Assim, o quanto antes ela possa tomar conhecimento e construir marcas de pertencimento, maior a possibilidade para se reconhecer como partícipe do mundo e das comunidades sócio-culturais de que participa, e, portanto, como sujeito responsável pela própria história e realidade. (OLIVEIRA, 2015, p.33)

\footnotetext{
${ }^{4}$ A declaração foi extraída de artigo do escritor Renato Pacheco, intitulado Introdução à história do livro capixaba, publicado na Revista da UFES, v. 10, n. 34, p. 65-68, 1985.
} 
Assim, descreveremos nesse artigo uma experiência com autores capixabas e a oficina de estratégias de leitura levada e aplicada na escola municipal do ensino fundamental Custódia Dias de Campos.

Apesar da boa vontade da bibliotecária que atua nessa instituição escolar em estimular a leitura literária dos alunos, é perceptível o privilégio aos livros de autores de fora do Espírito Santo no acervo. A dificuldade de encontrar os autores e os livros é mais uma vez apresentada como justificativa para a ausência, que leva à exclusão e a premissa de invisibilidade da produção literária infantil do Espírito Santo.

O livro João, o botão, da escritora Elizabeth Martins, repousava em meio aos livros provenientes das caixas do PNBE. Também a sistematização do acesso parece comprometida, pois o livro da escritora só foi mapeado em atendimento a pesquisa. Em depoimento anterior, no primeiro dia de vivência na biblioteca, a bibliotecária informou a inexistência de livros de autores do Espírito Santo. O que não é mais uma realidade após a pesquisa de campo, em virtude de uma das pesquisadoras ter doado alguns livros de escritores do Estado. Agora o acervo escolar conta com alguns títulos de autores regionais.

\section{O texto explícito e implícito}

A pesquisa teve o intuito de trabalhar a oficina por meio das estratégias de leitura com literatura infantil, direcionando o processo leitor não no aspecto da decodificação, mas ao contrário, na perspectiva de que os alunos, ao lerem, pudessem compreender o texto expresso explícita e implicitamente. $\mathrm{O}$ uso das estratégias teve seu foco na premissa de se buscar despertar na criança uma leitura não-utilitária, desobrigada, sem a perspectiva de enquadramento, mas a consecução de uma leitura de descobertas, imaginativa, fantasiosa, de modo a lhes propiciar a fruição e o prazer a partir da leitura literária e a compreensão do texto.

O professor, o bibliotecário, os pais, qualquer mediador, atuando como um facilitador tem a possibilidade de apontar possibilidades, as quais resultem em um mergulho na infinidade de descobertas e desvelamentos que a literatura é capaz de oportunizar aos leitores. Esse mapa, segundo Solé (1996), aponta para uma peculiaridade:

Uma das características das estratégias é o fato de que não detalham nem prescrevem totalmente o curso de uma ação. [...] Um componente essencial das estratégias é o fato de que envolvem autodireção - a existência de um objetivo e a consciência de que este objetivo existe e autocontrole, isto é, a supervisão e avaliação do próprio comportamento em função dos objetivos que o guiam e da possibilidade de modificá-lo em caso de necessidade. (SOLÉ, 1996, p.69)

A opção de uma das pesquisadoras por trabalhar as estratégias de compreensão leitora, tendo como referencial as publicações dos escritores que produzem livros para crianças no Espírito Santo se coaduna com o conceito de leitura literária, tendo o texto artístico, não como um momento único, desvinculado da realidade circundante mas, conforme Vera Teixeira de Aguiar,

ao contrário, salienta a multiplicidade de fatores aí presentes. O livro não se coloca num templo, acima e além do leitor, como objeto intocável, sagrado e detentor de uma verdade acabada e inquestionável, que se constrói por si mesma. Em oposição, é 
entendido como produto cultural ativo, integrado ao sistema de trocas da comunidade, desde sua criação até seu consumo, passando pelas ingerências de edição e circulação. [...] Assim dessacralizado, o livro tem as funções alargadas, uma vez que sua leitura é considerada como fato presente no cotidiano, prática social vivenciada entre as demais e relativizada segundo as regras e jogos sociais de que participa. (AGUIAR, apud EVANGELISTA, BRANDÃO e MACHADO (orgs.) 2006).

O uso das estratégias de compreensão leitora com livros de autores regionais teve a perspectiva de promover uma leitura de desfrute, porém, pautada em trabalhar-se a proximidade, a familiaridade, por meio da regionalidade textual. Foi acordado então, com os alunos e com a escola, uma seleção de livros de autores do Espírito Santo. E teve um segundo aspecto propositivo: contribuir para ampliar os estudos acadêmicos dessas obras além de, consequentemente, oportunizar a consolidação desses autores e de suas obras junto ao público leitor, auxiliando na sua difusão. Assegurando-se, a busca da formação de juízos de valor qualificados acerca desses autores e de suas obras.

Foram trabalhadas como foco central as obras literárias $O$ rabinho de porco (Francisco Aurélio Ribeiro), João, o botão (Elizabeth Martins), A casa rosa (Silvana Pinheiro), $O$ gato verde (Ilvan Filho) e Uma casinha lá no alto (Ilvan Filho). Apenas João, o botão pertencia ao acervo da biblioteca da EMEF Custódia Dias de Campos. E dos 21 alunos que participaram da oficina, somente dois recordavam a obra literária da escritora Elizabeth Martins. O livro $O$ rabinho de porco, está esgotado, e os participantes trabalharam o texto, sem as imagens.

\section{Primeiro contato na escola}

O primeiro contato de uma das pesquisadoras com a EMEF Custódia Dias de Campos se deu no ano de 2014, acompanhando o trabalho do escritor Ilvan Filho - com uma turma da escola, em visita a uma gráfica - visando coleta de dados para a pesquisa de Doutorado, concluída em agosto de 2015. A conversa dos alunos com o escritor e as indagações pertinentes e oportunas que surgiram chamaram-lhe a atenção. Os alunos mostraram-se interessados pela literatura infantil de seu Estado, e ficou evidente o desconhecimento da literatura e dos escritores locais; bem como a inquietude e indignação dos estudantes para com a falta de encorajamento e estímulo nas escolas ao estudo da literatura regional destinada às crianças.

No projeto de pós-doutoramento, mediante o contato com as estratégias de leitura adveio-lhe muito claramente o desejo em desenvolver a oficina com os alunos dessa mesma escola municipal, em face à experiência anterior de interesse e de próatividade dos estudantes. $\mathrm{O}$ grande fascínio em relação às estratégias de leitura com literatura infantil está na potencialidade comunicacional e empoderadora, capaz de forjar cidadãos; e na contramão do enfoque dado comumente ao livro literário no cotidiano de instituições escolares, como atestam Lima, Chaves e Giroto, apud Souza (2012) na obra Leitura e Cidadania - uma compilação de algumas de suas pesquisas acerca da leitura - que:

Não é raro que, no cotidiano de instituições escolares, seja possível partilharmos momentos em que as crianças ouvem histórias "para se acalmarem" ou leem no "cantinho da leitura" quando lhes sobra tempo, uma vez que os conteúdos das diferentes áreas do conhecimento parecem ser mais importantes que as histórias da 
Literatura. [...] particularmente, da literatura infantil - compreendida como forma de produção cultural para a infância - depreende-se a compreensão do quanto tem sido marcada pelo contexto histórico e por uma concepção que confere à criança a condição de mera expectadora frente às influências educativas do adulto, realizadas de forma direta ou indireta. (LIMA, CHAVES e GIROTTO, apud SOUZA 2012, p. 91 - 97)

As estratégias de compreensão leitora pressupõem a prática constante da dialogia, numa leitura polifônica, aberta às diversas vozes que advierem. $\mathrm{O}$ mediador tem que estar comprometido com o ensino das estratégias, e numa perspectiva horizontalizada, de troca, com os seus interlocutores. Há uma demanda pela leitura livre dos textos, ou seja, sem o propósito de ensinar uma temática específica. Desprovido então de didatização, o professor deve deixar-se envolver e entrelaçar-se com os jovens leitores na polissemia dos textos, como observa Jean Marie Goulemot, em seu artigo A leitura como produção de sentidos, em Práticas de Leitura, esquecido das dimensões psicopedagógicas da leitura e de seu aprendizado (CHARTIER, 2011, p. 107-116). Foi nessa vertente que se deu a experiência prática com as estratégias de leitura com literatura infantil na EMEF Custódia Dias de Campos.

No primeiro semestre de 2016 houve uma imersão de uma das pesquisadoras nos estudos promovidos no Centro de Estudos em Leitura e Literatura Infantil e Juvenil (CELLIJ), da Faculdade de Ciência e Tecnologia, Unesp-PP, com a metodologia das estratégias de leitura, sob a supervisão da coordenadora do espaço. O CELLIJ foi criado em 1995 com o intuito de formar leitores a partir do texto literário e de proporcionar um diálogo direto com professores, jovens alunos, instâncias governamentais responsáveis pela implementação de políticas públicas no campo da Educação. O intercâmbio propiciou um diagnóstico prévio e a aplicação da metodologia, como primeira experiência no Estado do Espírito Santo.

Em abril de 2016 foi formalizado o contato com a pedagoga da escola, Fabrícia Freitas, e concedida a autorização para a realização da pesquisa no ambiente escolar. Nessa ocasião, estabeleceu-se a metodologia e o cronograma de três meses - setembro, outubro e novembro, para a pesquisa-ação, e que acabou por se estender um pouco mais, até dezembro. A Oficina de estratégias de leitura com livros produzidos por autores do Espírito Santo na EMEF Custódia Dias de Campos elegeu a biblioteca como espaço mais propício ao desenvolvimento do trabalho.

Em agosto houve a realização de mais um encontro com a pedagoga da escola, e foi explicitada a dinâmica de trabalho por parte de uma das pesquisadoras, ocasião em que foi promovida a apresentação à bibliotecária e definida a turma - um quarto ano matutino do ensino fundamental - com o delineamento do perfil do alunado. Desse modo, ficou estabelecida a sexta-feira como o dia de prática da oficina no ambiente da biblioteca escolar, uma vez que esse é o momento em que os 21 alunos, com idade entre 9 e 10 anos, vivenciavam uma prática espontânea da literatura na escola. As crianças foram divididas em três grupos de sete alunos - o espaço na biblioteca é bastante reduzido - e eles passam 40 minutos em contato com a leitura literária.

Mas na biblioteca não se dá apenas o desenvolvimento de atividades literárias. $\mathrm{Na}$ primeira visita ao espaço e para apresentação aos alunos, em 16 de setembro, o primeiro grupo foi encontrado de frente para a televisão, assistindo a um filme, "Viagem ao Centro da Terra", inspirado na obra do escritor Júlio Verne. Segundo a bibliotecária, enquanto esperavam pela chegada de uma das pesquisadoras, foi-lhes oferecido um filme, para distração, apesar das estantes estarem abarrotadas de livros. 


\section{Conexão texto-texto}

A espantosa intrusão da TV na biblioteca oportunizou uma primeira conversa literária com uso da estratégia da conexão, com enfoque no autor. A partir do desvio acidentalmente oportunizado pela bibliotecária, seguiu-se um atalho: falar de Júlio Verne, escritor que conseguiu unir a literatura e a ficção científica de maneira apaixonante e que por tamanha genialidade literária, vem sendo lido até hoje e que teve algumas de suas obras traduzidas para filme. Foi-lhes então apresentada a estratégia texto-texto (filme) e os alunos foram interpelados acerca do conhecimento de outras obras do escritor francês.

O grupo então desconectou-se do audiovisual e iniciou uma conversa sobre outras obras literárias do escritor e migrou, posteriormente, para a análise de outros livros. Girotto e Souza (2010) atestam que "o propósito de fazer conexões é aumentar o entendimento para que o pensamento da criança não escape para outras áreas completamente alheias ao texto". Ao conseguir atrair o interesse dos estudantes para a literatura, permitiu a que a pesquisadora-oficineira pudesse prestar esclarecimentos sobre a proposta das oficinas.

O grupo de estudantes foi informado e orientado sobre os procedimentos adotados nas oficinas de leitura, de que lhes seria modelada uma aula de estratégias, para cada grupo, e que eles colocariam as estratégias em prática, a partir daí. Segundo Girotto e Souza,

O modelo de oficina enfatiza a escolha na seleção do livro. [...] os alunos, assim, podem escolher qualquer livro que estiver à disposição, ou podem optar por aqueles indicados pelo professor. [...] refere-se a isso como "escolha orientada/dirigida". (GIROTTO e SOUZA, apud, MENIN, GIROTTO, ARENA e SOUZA, 2010, p. 59-60)

Nesta proposta de oficina privilegiou-se a adoção do modelo de escolha orientada-dirigida, contemplando textos paradidáticos e literários. Estes últimos como veículos da arte se valem da ficção, da linguagem poética, da ambiguidade e tem uma motivação estética, sendo também uma maneira particular de se representar o mundo. Já os chamados paradidáticos, são ficcionais, mas aproveitam a narrativa criada para transmitir informação, formação e conformação. A narrativa é hibridizada com um caráter utilitário bastante notável.

O escritor e ilustrador Ricardo Azevedo, faz diferenciação nessas modalidades de livros direcionados às crianças e jovens, ressaltando que devem ser examinados em virtude de dirimir confusões e para não influir negativamente no processo de formação dos leitores. Azevedo ressalta a diferenciação:

Os livros paradidáticos: também essencialmente utilitários, constituídos de informações objetivas que, em resumo, pretendem transmitir conhecimento e informação. Em geral, abordam assuntos paralelos ligados às matérias do currículo regular, de forma a complementar aos livros didáticos. [...] É importante lembrar que o grupo dos paradidáticos pode apresentar diferentes graus de didatismo. Fazem parte do mesmo conjunto obras praticamente equivalentes ao livro didático e outras onde a ficção se destaca. São aquelas que, através de uma história inventada, pretendem ensinar o leitor a não ter medo do dentista ou a amar a natureza. Em outras palavras, mesmo lançando mão da ficção e da linguagem poética, os livros paradidáticos têm sempre e sempre o intuito final de passar algum tipo de lição ou infomação objetiva e esclarecedora. A 
literatura costuma tratar de assuntos, subjetivos por princípio, sobre os quais não tem cabimento dar aula: a paixão, a morte, a busca do autoconhecimento, a amizade, a alegria, os afetos, as perdas, o desconhecido, o imensurável (o gosto, o prazer, o amor, a beleza etc.), a busca da felicidade, a astúcia, o ardil, os sonhos, a dupla existência da verdade, a relatividade das coisas, a injustiça, o interesse pessoal versus o coletivo, o livre arbítrio, a passagem inexorável do tempo, o paradoxal, o conflito entre o velho e o novo etc. Na verdade, ela pode falar de qualquer tema, todos os abordados pelos paradidáticos por exemplo, desde que o mesmo seja visto pelo ângulo da ficção, da subjetividade e da poesia. (AZEVEDO, 1999, p. 92-102)

Para o autor (1999) a ausência de explicitação das características e das fronteiras entre os livros dirigidos ao público infantil e juvenil pela indústria editorial tem causado uma grande confusão nos leitores. Há necessidade de que seja estabelecida uma nitidez em cada modalidade a fim de assegurar uma homogeneidade classificatória. De acordo com o pesquisador a indiferenciação entre as obras tem confundido, autores, editores, professores, críticos e consequentemente os leitores, contribuindo para o seu afastamento da leitura literária. E como é propósito desse estudo a formação de leitores com livros infantis e juvenis produzidos para crianças no Espírito Santo, e sendo predominante a quantidade de paradidáticos, sobressaindo-se aos literários, cumpre acenar para a sua delimitação conceitual.

\section{Atividade diagnóstica}

No segundo contato, foi realizada a Atividade Diagnóstica de Leitura Literatura do Espírito Santo. Composta por 8 de questões de compreensão leitora e uma de conhecimento prévio. Ao ser analisado, o diagnóstico fornece indícios de uma dificuldade de interpretação dos textos propostos. Outra evidência relaciona-se à hipótese de desconhecimento por parte dos alunos da produção literária e de livros paradidáticos no Estado. A esse respeito, sobre o conhecimento prévio de autor capixaba, dos 21 estudantes, 14 deixaram essa pergunta em branco - afirmaram não conhecer - 6 responderam o nome de uma obra, ao invés do autor; e apenas 1 soube dizer o nome do escritor.

O diagnóstico trabalhou com a linguagem dos quadrinhos, que mescla a narrativa verbal e a não verbal, e registrou-se, além de uma satisfação e uma maior familiaridade, verbalizada pelos estudantes, essa questão obteve o acerto de todos do grupo pesquisado. O uso das histórias em quadrinhos em uma questão do diagnóstico permitiu confirmar a receptividade ao uso das estratégias de conexão, sobretudo a conexão texto-mundo, que a priori foi bastante utilizada no decorrer da oficina.

$\mathrm{Na}$ terceira questão do diagnóstico, mencionada no parágrafo anterior, o leitor é levado a fazer uma conexão texto-mundo. Há um questionamento mais óbvio, de qual quadrinho faz referência à montanha mencionada no poema exposto. $\mathrm{O}$ nome da montanha é evidenciado três vezes na poesia, e ainda está escrito no quadrinho. No entanto, o mais contundente é o fato de que todas as montanhas explicitadas nos quadrinhos, serem notórias e de conhecimento dos moradores do Estado do Espírito Santo, o que permitiu a explicitação da conexão texto-mundo. As crianças mencionaram o reconhecimento das montanhas e atestaram o conhecimento prévio de localização e/ou o reconhecimento de ter estado em contato com pelo menos duas dessas montanhas, sendo que a montanha intitulada Pedra dos Dois Olhos, foi a mais mencionada, pela 
proximidade com a casa da maioria deles, o que demonstra o quanto o conhecimento prévio é capaz de suscitar familiaridade e proximidade do leitor com o texto lido.

\section{As oficinas de estratégias}

Fazer com que os alunos ao lerem atribuam significado ao que leram, sabendo inferir sobre a obra lida, foi uma das premissas da Oficina de estratégias de leitura com livros produzidos por autores do Espírito Santo na EMEF Custódia Dias de Campos. Embora sejam sete as estratégias de leitura, (SANTOS e SOUZA, 2011, p.30): conhecimento prévio, conexões, inferência, visualização, perguntas ao texto, sumarização e síntese; das sete, foram utilizadas apenas cinco, na oficina. Santos e Souza (2011) explicam cada uma:

O conhecimento prévio é a base para as outras estratégias de leitura, porque o leitor não consegue entender o que está lendo sem pensar naquilo que já conhece. [...] é definido pelos norte-americanos como estratégia-mãe ou estratégia guarda-chuva, pois agrega todas as demais. [...] As conexões são fáceis de serem compreendidas. Elas podem se dividir em três espécies: texto-leitor, texto-texto e textomundo. Na conexão texto-leitor, os alunos são estimulados a perceberem as relações entre o texto lido e suas experiências. [...] As conexões texto-texto acontecem quando, na leitura, o leitor faz conexão com outros textos lidos. [...] Já a conexão texto-mundo é usada para que as crianças entendam a relação entre o texto lido e o mundo que as rodeia. [...] A inferência é uma conclusão lógica feita pelo leitor, baseada em pistas encontradas no texto, que não são diretamente confirmadas pelo autor. A estratégia de visualização é como aquela que traz alegria ao ato de ler. Visualizar é formar imagens mentais que pertencem somente àquele leitor e a mais ninguém. [...] fazer perguntas ao texto, leva as crianças a esclarecerem informações. [...] Sumarizar, ou determinar a importância do texto. [...] Síntese [...] a síntese lida com a organização. (SANTOS e SOUZA, 2011, p.30-35)

O primeiro livro apresentado aos alunos foi $O$ gato, do escritor brasileiro Bartolomeu Campos de Queiroz. A partir da apresentação desse livro uma estudante fez uma conexão texto-leitor, rememorou o nome do seu cão, que se chama Bartolomeu; já outro aluno fez uma conexão texto-texto, lembrou do livro $O$ gato verde, de Ilvan Filho, um autor que produz livros no Espírito Santo e que ele já havia lido.

Ambos estudantes utilizaram, sem intencionalidade e racionalidade, ou seja, naturalmente, as estratégias de leitura com o texto literário ofertado a eles. E estabeleceram relações com situações e conhecimentos prévios. Essas conexões, se utilizadas racionalmente, podem propiciar aos leitores em construção, uma autonomia e uma apreensão melhor do que lêem. Esse é um dos propósitos ensejados na formação com estratégias de leitura, conforme Solé,

Em síntese, porque queremos formar leitores autônomos, capazes de enfrentar de forma inteligente textos de índole muito diversa, na maioria das vezes diferentes dos utilizados durante a instrução. Esses textos podem ser difíceis, por serem muito criativos ou por estarem mal escritos. De qualquer forma, como correspondem a uma grande variedade de objetivos, cabe esperar que sua estrutura também seja variada, assim como sua possibilidade de compreensão. Formar 
leitores autônomos também significa formar leitores capazes de aprender a partir dos textos. Para isso, quem lê deve ser capaz de interrogar-se sobre sua própria compreensão, estabelecer relações entre o que lê e o que faz parte do seu acervo pessoal, questionar seu conhecimento e modifica-lo, estabelecer generalizações que permitam transferir o que foi aprendido para outros contextos diferentes... (SOLÉ, 1996, p.72)

No que diz respeito a transferências do que foi aprendido para outros contextos, durante o trabalho na Oficina de estratégias de leitura com livros produzidos por autores do Espírito Santo na EMEF Custódia Dias de Campos, houve um momento memorável com a obra literária Uma casinha lá no alto, escrito e ilustrado por Ilvan Filho. A narrativa não-linear, faz uma retrospectiva da lenda de criação do Convento da Penha, patrimônio histórico do Espírito Santo. Todos os alunos ao lerem a obra, e explaná-la, rememoraram o estudo na disciplina de História, do período da Colonização, e mencionaram passagens da aprendizagem em sala de aula. O momento com o livro literário na biblioteca, suscitou a recordação e reflexão sobre o conteúdo aprendido na disciplina de sala de aula, tanto pela leitura textual, como das ilustrações.

Leitores estratégicos são aqueles que ouvem a voz interior e dialogam com ela, como numa conversa interna. Como nos coloca Souza e Girotto (2010), eles procuram respostas para suas perguntas. Tentam entender melhor o texto, por meio de suas conexões com os personagens, situações e problemas. Mediante o arcabouço das estratégias de compreensão leitora, o leitor estratégico, em estado de atenção e prontidão, tem o domínio e é capaz de acessar os conhecimentos necessários para propiciar a atribuição de significado aos conteúdos dos variados textos. Exatamente como ocorreu com a obra literária Uma casinha lá no alto, que oportunizou o uso de diversas estratégias de leitura, tais como conhecimentos prévios, conexão texto-leitor, conexão texto-texto, conexão texto-mundo, visualização e inferência.

A clareza, a coerência do conteúdo e/ou o conhecimento de sua estrutura são atributos indispensáveis a um texto, de maneira a que este facilite a vida do leitor e se deixe compreender. Para Solé o texto em si deve se deixar compreender e o leitor deve possuir conhecimentos adequados para elaborar uma interpretação sobre ele.

A crença dessa pesquisa de que a experiência com a literatura regional pode convocar os jovens leitores a desenvolverem maior proximidade com os textos lidos, e assim terem oportunizada uma melhor compreensão leitora, é acrescida ainda de uma outra suposição, de que o fato da obra artística ser de um escritor do seu entorno, haja também um estímulo ao exercício criativo, fantasioso e imaginativo. Tal premissa se sedimenta no ponto de vista de ao relacionar as bases experimentais e experienciais como propulsoras do ato imaginativo. Dagoberto Buim Arena, suscita uma reflexão de Vygotsky:

A imaginação origina-se exatamente desse acúmulo de experiência [...] consiste na afirmação da necessidade de ampliar a experiência da criança, caso se queira criar as bases suficientemente sólidas para a sua atividade de criação. Quanto mais a criança viu, ouviu e vivenciou, mais ela sabe e assimilou, quanto maior a quantidade de elementos da realidade de que ela dispõe em sua experiência - sendo as demais circunstâncias das mesmas -, mais significativa e produtiva será a atividade de sua imaginação. (VYGOTSKY, apud, GIROTTO e SOUZA, apud, MENIN, GIROTTO, ARENA e SOUZA, 2010, p.31)

Durante a Oficina de estratégias de leitura com livros produzidos por autores do Espírito Santo na EMEF Custódia Dias de Campos as crianças tiveram contato não 
somente com as narrativas literárias, de escritores de seu Estado, mas puderam conversar com o escritor, Ilvan Filho, autor do livro Uma Casinha lá no Alto, que compareceu à biblioteca da escola, para uma conversa sobre $o$ seu processo de criação da obra. Por meio desse contato, os estudantes sentiram-se impelidos ao ato criativo, como um espelhamento. Também tiveram a oportunidade de visitar uma estância rural, para o reconhecimento de alguns personagens do livro $O$ rabinho de porco, do escritor Francisco Aurélio Ribeiro. Essa experiência foi para muitas crianças o primeiro contato com alguns dos bichos-personagens do livro, os quais não conseguiam materializar, e portanto, não conseguiam imaginar-lhes, conferindo-lhes forma aproximada que fosse.

O livro A casa rosa, de Silvana Pinheiro, foi a obra que mais propiciou o uso das conexões e até mesmo de inferências. Muitas casas foram acessadas na memória dos pequenos, e como a história mencionava chegadas e partidas na casa, quase que por unanimidade os participantes da oficina rememoraram um colega querido, que havia deixado a escola e se mudado para o Canadá. Ao rememorarem o amigo que perderam, as crianças usaram a conexão texto-leitor, pois o texto conectou-os com a dor que sentiram do amigo que partira. E usaram a mesma conexão ao recordar as casas de vizinhos e parentes pintadas de cor rosa. Ativaram a relação com o contexto e, consequentemente, isso lhes conferiu pertencimento, envolvendo-os na história por familiaridade.

Essa obra literária ainda propiciou o uso de inferências, sobre os pertences que os moradores da Casa Rosa deixavam para trás. Foi criado um "quadro âncora", e as crianças tentavam adivinhar o que o poeta, que morou na casa, deixou para trás. E associando-se o recurso da visualização, foram levados a inferir acerca dos cacarecos sem aparente utilidade que o cientista abandonou na casa. Harvey e Goudvis, apud, Menin, Girotto, Arena e Souza, 2010, p.85, reflete que as imagens criadas pelos leitores, por meio da visualização, são profundamente pessoais e fazem com que a experiência da leitura se torne mais prazerosa e permita o engajamento na prática literária.

Também usaram da inferência para descobrir o significado de palavras desconhecidas, como na história do rapaz que perdera a razão por uma moça. Os estudantes procuraram deduzir o significado de perder a razão. Para tanto, foi preparado pela monitora/pesquisadora, um "cartaz âncora". O cartaz, afixado na parede, tinha três colunas: uma com a sentença escrita, a outra, com o significado inferido, e na outra as dicas do texto. Cada criança foi até o cartaz, e escreveu sua inferência e as dicas do texto para compreensão da expressão. Ao final a monitora/pesquisadora, pediu-lhes que fizessem uma pesquisa em casa sobre a sentença "perder a razão". E, no encontro seguinte, houve o desvelamento.

Diante de uma outra obra, João, o botão, da escritora Elizabeth Martins, a imaginação levou os integrantes da oficina para dentro dos armários dos pais, mães, tios e avós. A conexão texto-leitor alinhavou as memórias de ternos esquisitos, vestidos esquecidos e outras tantas vestimentas rejeitadas. A história do botão que ansiava por um lar feliz, trouxe ao debate a estratégia de visualização. Girotto e Souza, explicam que:

Visualizar é, sobretudo, inferir significados, por isso visualização é uma forma de inferência, justificando a razão dessas duas estratégias, serem abordadas tão proximamente. Quando os leitores visualizam, estão elaborando significados ao criar imagens mentais, isso porque criam cenários e figuras em suas mentes enquanto leem, fazendo com que eleve o nível de interesse e, assim, a atenção seja mantida. (GIROTTO e SOUZA, apud, MENIN, GIROTTO, ARENA E SOUZA, 2010, p.85) 
Cada criança produziu um quadro de visualização, contemplando seu nome e a série e o que ela visualizava, ou seja, quais personagens de seu cotidiano. E ainda responderam se essa visualização causava-lhes alguma reação emocional, como alegria, tristeza, saudade, etc. Nesse caso, as crianças transportaram a si mesmas para dentro do texto, o que as fez se envolverem com a obra e a leitura. Quando os leitores visualizam estão invocando os seus conhecimentos prévios e articulando-os ao seu contexto e a situações do texto. Alonso Tapia reflete que:

A compreensão é um processo de busca de significado, no qual o sujeito realiza um encontro consigo mesmo e o mundo externo e articula estes elementos na construção de um outro conhecimento. [...] para compreender a língua de forma adequada, é necessário que esteja conectada com os contextos em que é utilizada. (ALONSO TAPIA, apud, BITTENCOURT, CARVALHO, JUHAS E SCHWARTZ, 2015, p. 14)

A experiência com as estratégias de compreensão leitora, envolvendo autores que produzem literatura no Espírito Santo, por meio de oficinas, realizadas na biblioteca, com alunos do quarto ano do ensino fundamental, suscitaram o prazer e a alegria, e evidenciaram que a fruição literária pode e deve permear os processos de ensino e aprendizagem no ambiente escolar. $\mathrm{O}$ interesse pela leitura de um livro é em muitos casos retroalimentado pelo contexto, que suscita no leitor uma motivação para o ato de ler. A conexão texto-leitor é uma das estratégias determinantes no desenvolvimento da motivação da leitura, é onde o leitor encontra a semântica do livro que está lendo. A pesquisa realizada com as oficinas na escola capixaba acena para a possibilidade de o repertório literário regional contribuir para expandir a compreensão e a construção de sentidos do leitor.

\section{Referencial}

AGUIAR, Vera Teixeira, in A escolarização da leitura literária - o jogo do livro infantil e juvenil. Belo Horizonte, Editora Autêntica, 2006.

AZEVEDO, Ricardo. Artigo Livros para crianças e literatura infantil: convergência e dissonâncias, publicado na Revista "Signos" Ano $20 \mathrm{n}^{\mathrm{a}}$ 1, Lajeado, Univates, 1999, p. 92- 102, ISSN 1413-0416.

CHARTIER, Roger. Práticas da Leitura. São Paulo, Editora Estação Liberdade, 2011.

FILHO, Ilvan. O gato verde. Vitória, Gráfica e Editora GSA, 2011.

FILHO, Ilvan. Uma Casinha lá no alto. Vitória, Gráfica e Editora GSA, 2013.

HUNT, Peter. Crítica, teoria e literatura infantil. São Paulo: Cosac Naif, 2010.

MARTINS, Elizabeth. João, o botão. Vitória, Editora Independente, 1999.

OLIVEIRA, Ivana Esteves Passos de. O desvelar do autor, produtor, divulgador $e$ distribuidor de Livro Infantil no Espírito Santo no século XXI. Tese de doutorado em Letras/ Universidade Federal do Espírito Santo. 
PACHECO, Renato. Introdução à história do livro capixaba. Revista da UFES, v. 10, n. 34, p. 65-68, 1985.

QUEIROZ, Bartolomeu Campos de. O gato. São Paulo, Editora Paulinas, 2014.

RIBEIRO, Francisco Aurélio. A Literatura do Espírito Santo: uma marginalidade periférica. Vitória: Nemar, 1996.

RIBEIRO, Francisco Aurélio. O rabinho do porco. Serra, Grupo Formar, 2004.

SANTOS, Ana Maria Martins da Costa E SOUZA, Renata Junqueira de. Andersen e as estratégias de leitura - atividades práticas no cotidiano escolar. Campinas, Mercado de Letras Edições e Livraria Ltda, 2011.

SOLÉ, Isabel. Estratégias de leitura. São Paulo, Artmed Editora, 1996.

SOUZA, Renata Junqueira de (org.), et al MENIN, Ana Maria da C.S, GIROTTO, Cyntia Graziella G.S. Ler e compreender: estratégias de leitura. Campinas, Mercado de Letras Edições e Livraria Ltda, 2010.

SOUZA, Renata Junqueira de e LIMA, Elieuza Aparecida de, (orgs.) Leitura $e$ Cidadania. Campinas, Mercado de Letras Edições e Livraria Ltda, 2012.

ZILBERMAN, Regina. A literatura infantil na Escola. São Paulo: Global, 2003.

Recebido em 21 de abril de 2019

Aceito em 20 de setembro de 2019 